\title{
Stakeholders' perception of the nutrition and health claim regulation
}

Citation for published version (APA):

de Boer, A., \& Bast, A. (2015). Stakeholders' perception of the nutrition and health claim regulation. International Journal of Food Sciences and Nutrition, 66(3), 321-328.

https://doi.org/10.3109/09637486.2014.986071

Document status and date:

Published: 01/05/2015

DOI:

10.3109/09637486.2014.986071

Document Version:

Publisher's PDF, also known as Version of record

Document license:

Taverne

Please check the document version of this publication:

- A submitted manuscript is the version of the article upon submission and before peer-review. There can be important differences between the submitted version and the official published version of record.

People interested in the research are advised to contact the author for the final version of the publication, or visit the DOI to the publisher's website.

- The final author version and the galley proof are versions of the publication after peer review.

- The final published version features the final layout of the paper including the volume, issue and page numbers.

Link to publication

\footnotetext{
General rights rights.

- You may freely distribute the URL identifying the publication in the public portal. please follow below link for the End User Agreement:

www.umlib.nl/taverne-license

Take down policy

If you believe that this document breaches copyright please contact us at:

repository@maastrichtuniversity.nl

providing details and we will investigate your claim.
}

Copyright and moral rights for the publications made accessible in the public portal are retained by the authors and/or other copyright owners and it is a condition of accessing publications that users recognise and abide by the legal requirements associated with these

- Users may download and print one copy of any publication from the public portal for the purpose of private study or research.

- You may not further distribute the material or use it for any profit-making activity or commercial gain

If the publication is distributed under the terms of Article $25 \mathrm{fa}$ of the Dutch Copyright Act, indicated by the "Taverne" license above, 


\section{Stakeholders' perception of the nutrition and health claim regulation}

\section{Alie de Boer \& Aalt Bast}

To cite this article: Alie de Boer \& Aalt Bast (2015) Stakeholders' perception of the nutrition and health claim regulation, International Journal of Food Sciences and Nutrition, 66:3, 321-328, DOI: 10.3109/09637486.2014.986071

To link to this article: https://doi.org/10.3109/09637486.2014.986071

\section{曲 Published online: 13 Jan 2015.}

Submit your article to this journal $\sqsubset$

Џll Article views: 370

Q View related articles $\asymp$

View Crossmark data 4

Citing articles: 6 View citing articles $\square$ 


\title{
Stakeholders' perception of the nutrition and health claim regulation
}

\author{
Alie de Boer and Aalt Bast \\ Department of Toxicology, Maastricht University, Maastricht, The Netherlands
}

\begin{abstract}
In 2007, the Nutrition and Health Claim Regulation (NHCR) entered into force, which required scientific substantiation of health claims. In the field of antioxidants, most proposed claims were negatively assessed by the European Food Safety Authority (EFSA). This study reviews the perception of the NHCR of 14 Dutch stakeholders to unravel the grounds for disproving the putative health claims. Most claims are shown to be refused based on the quality of scientific substantiation, due to usage of scientific methods on which no consensus has been reached and the differences in expectations and requirements. Three themes exemplify the need for improvement in applying the NHCR: (i) enforcement; (ii) methodology; and (iii) perceived impact of the NHCR. With highly diverging perceptions of stakeholders, the current effectiveness of the NHCR can be questioned. The views of different stakeholders on these themes help to focus the discussion on the NCHR in capturing health effects.
\end{abstract}

\author{
Keywords \\ Antioxidants, bioactive compounds, \\ biomarker, functional food, health food, \\ healthy benefits, nutrition
}

\section{History}

Received 2 June 2014

Revised 21 October 2014

Accepted 29 October 2014

Published online 13 January 2015

\section{Introduction}

Following the reform of European food law in the aftermath of the bovine spongiform encephalopathy (BSE) crisis, a new regulatory framework dealing with nutrition and health claims entered into force in the EU in 2007: the Nutrition and Health Claim Regulation $^{1}$ (NHCR) (Gilsenan, 2011; Moors, 2012). The NHCR aims to protect consumers from misleading by incorrect information and false claims by ensuring that proposed claims are scientifically substantiated. Moreover, the NHCR is intended to improve the free movement of goods in the internal market by harmonizing the various national regulations of Member States (European Parliament and the Council, 2006; Gilsenan, 2011; Hoad, 2011; Moors, 2012). The use of a claim is permitted or refused by the European Commission (EC), after consulting the expert opinion of the European Food Safety Authority (EFSA). EFSA is the independent agency advising the EC on the accuracy of the scientific basis of a claim through a set of different criteria (EFSA, 2014a,d).

The NHCR regulates both nutrition and health claims. Nutrition claims describe the nutritional properties of the ingredient or food product. Health claims state the relationship between the ingredient or food product and a beneficial effect on health (European Parliament and the Council, 2006). Health claims can be divided into three categories: (i) article 13.1 claims: general function claims, implying a health benefit based on scientific evidence (EFSA, 2012); (ii) article 13.5 claims: new function claims, implying a health benefit based on newly

Correspondence: Ms Alie de Boer, MSc, Department of Toxicology, Maastricht University, P.O. Box 616, 6200 MD Maastricht, The Netherlands. E-mail: a.deboer@maastrichtuniversity.nl

${ }^{1}$ Regulation (EC) No. 1924/2006 of the European Parliament and of the Council of 20 December 2006 on nutrition and health claims made on foods. Regulation (EC) No. 1924/2006 is amended by Regulation (EC) No. 107/2008; Regulation (EC) No. 109/2008; Commission Regulation (EU) No. 116/2010; and Commission Regulation (EU) No. 1047/2012. developed scientific evidence (EFSA, 2014c); and (iii) article 14 claims: claims on (a) the reduction of disease risk or on (b) children's development and health (EFSA, 2014b; European Commission, 2013; European Parliament and the Council, 2006). Approved article 13.1 and 13.5 claims are made public in the annex to Regulation 432/2012 ${ }^{2}$ (EFSA, 2012). New ECauthorized article 13.5 claims are continuously added to this list (Verhagen et al., 2010). Currently, the EC authorized 233 claims (European Commission, 2012). EFSA considered nearly all proposed article 13.1 claims on antioxidants were not substantiated satisfactorily, leading the EC to decline these claims (de Boer et al., 2014; European Commission, 2013). Only eight claims on antioxidant activity received a positive advise and were subsequently authorized by the EC, viz. seven claims on vitamins and minerals, one claim on olive oil polyphenols (European Commission, 2013). Positive opinions from EFSA on watersoluble tomato concentrate (NDA Panel EFSA, 2009, 2010) and on cocoa flavonoids (NDA Panel EFSA, 2012) are not taken into account here, since the claimed health benefits of these products are not regarded as consequence of antioxidants as the active ingredient (de Boer et al., 2014).

Only very few statements about ingredients acting as antioxidant or their health effects are currently allowed (Europe Press Releases, 2006; European Commission, 2013). In order to unravel the ground(s) for disproving the putative health claims of all virtual antioxidants, this study reviews the perception of stakeholders of the NHCR. This was investigated by conducting semistructured in-depth interviews with stakeholders in the

\footnotetext{
${ }^{2}$ Commission Regulation (EU) No. 432/2012 of 16 May 2012 establishing a list of permitted health claims made on foods, other than those referring to the reduction of disease risk and to children's development and health. Regulation 432/2012 is amended by Commission Regulation (EU) No. 536/2013; Commission Regulation (EU) No. 851/2013; Commission Regulation (EU) No. 1018/2013; and Commission Regulation (EU) No. 40/2014, adding seven article 13.1 and four article 13.5 claims to the list found in the Annex.
} 
Netherlands, working with functional ingredients and specifically antioxidant containing ingredients. Following Freeman's definition of stakeholders (1984): "any group or individual who can affect or is affected by the achievement of the [organization's] objectives', for the purpose of this four study groups were identified as stakeholders of the NCHR, viz. industrials (who have to live up to the requirements following the NHCR for current and future claims), regulatory experts (either involved in discussions on the development of the positive list or in enforcing the NHCR), nutritional scientists (affected by the required standards for scientific substantiation) and consumer representatives (serving as spokespersons for consumers, who are facing claims as marketing statements) (Bremmers et al., 2013; Ernst \& Young, 2012; Freeman, 1984).

\section{Methods}

For the purpose of this research a qualitative approach was followed, since qualitative research gives the opportunity to extensively explore the experiences of the involved stakeholders (Ritchie \& Lewis, 2003). By conducting semi-structured in-depth interviews in person it was possible to review the perception of stakeholders of the NHCR and their attitude about the procedures surrounding this regulation (DiCicco-Bloom \& Crabtree, 2006).

\section{Theoretical framework}

Through literature research and obtained expert opinions three themes were identified, which are expected to influence a stakeholder's view on the NHCR: (i) the regulatory act itself; (ii) the assessment procedure; and (iii) the impact of the regulation.

Expectations a stakeholder had of the regulatory act during the drafting process of the NHCR are assumed to influence the perception, as expectations prior to the occurrence of an event are described to influence the perception of that event (Oliver, 1980; Woodruff et al., 1983). In addition, current experience in dealing with the regulation is expected to affect perception. Since the EC decision is based on the scientific opinion of EFSA, the assessment procedure is expected to influence a stakeholder's view of the NHCR. Next to that, the credibility of this assessment process depends partially on transparency and independence of EFSA (Jensen \& Sandøe, 2002; Klintman \& Kronsell, 2010; Kobusch, 2010; Levidow \& Carr, 2007; Schreider et al., 2010).

The NHCR aims to stimulate innovation through the use of approved health claims, and therefore the impact on innovation is considered in the third variable (European Parliament and the Council, 2006). Since innovation is highly connected to research, a stakeholder is expected to link the effect on innovation to the impact of the NHCR on research (Mansfield, 1991; Nelson, 1993).

\section{Selection of participants}

In total, 14 Dutch professionals participated in this study (Table 1). In line with the theoretical framework set forth above, the four groups of stakeholders that are affected by the NHCR through different positions were approached: industrials, regulatory experts, nutritional scientists and consumer representatives (Freeman, 1984). Since this study focuses specifically on the NHCR and processes related to the NHCR and concentrates on food products containing antioxidants, key players were identified and by means of purposive sampling invited to participate in this study (Tansey, 2007). Although this type of non-probability sampling could limit the generalizability of results, the number of experts in the field is very limited and to reach the objective of this study, this methodology is considered to be appropriate (Lucas, 2014; Tansey, 2007). The identified key
Table 1. Overview of stakeholder participation.

\begin{tabular}{ccccc}
\hline & Industrials & $\begin{array}{c}\text { Regulatory } \\
\text { experts }\end{array}$ & $\begin{array}{c}\text { Nutritional } \\
\text { scientists }\end{array}$ & $\begin{array}{c}\text { Consumer } \\
\text { representatives }\end{array}$ \\
\hline $\begin{array}{c}\text { Approached } \\
\text { stakeholders }\end{array}$ & $7 *$ & 3 & 5 & 2 \\
$\begin{array}{c}\text { Declined } \\
\text { invitations }\end{array}$ & 0 & 1 & 2 & 0 \\
$\begin{array}{c}\text { Participating } \\
\text { stakeholders }\end{array}$ & $7 *$ & 2 & 3 & 2 \\
\hline
\end{tabular}

* = includes 3 food supplement industrials and 4 food industrials.

players were invited to participate in the study by e-mail. In this invitation e-mail, the aim of the study was explained as follows (translated from Dutch): "By conducting this research we want to identify how various stakeholders (industrials, regulatory experts, nutritional scientists and consumer representatives) perceive the use of the Nutrition and Health Claim Regulation within the field of food products containing antioxidants, which aspects are considered positive and what could be improved'.

Following the conducted interviews, each interviewee was asked to suggest possible participants to ensure a sufficient amount of stakeholders (Tansey, 2007). These individuals were, if not involved in the study already, contacted to participate. Although such snowball sampling is suggested to give a higher chance for participation of experts with more social connections, the small amount of experts in the field of antioxidants led to the need to include this type of sampling to ensure sufficient participants to reach the objective of the study (Lucas, 2014; Tansey, 2007). Even though most interviewees suggested already participating stakeholders, new participants were invited until no new findings were extracted in the data analysis from the conducted interviews and therefore the point of saturation was reached, leading to 14 participants in this study (Mason, 2010; Tansey, 2007).

\section{Data collection}

Semi-structured in-depth interviews with the participants were based on the theoretical framework (section "Theoretical framework'). All interviews were individually conducted in person by the first author. This set-up gave the possibility to ask in-depth questions to the interviewees to review their perception of the NHCR and the procedures surrounding this regulation (DiCiccoBloom \& Crabtree, 2006). During the interviews, all participating professionals were confronted with comparable questions. ${ }^{3}$ Following the introduction, explaining the objective of the interview, the interviewee was asked how he or she came into contact with the regulation, to clarify the position of the interviewee. Secondly, expectations and experience were addressed, and the objectives of the regulation were discussed. Subsequently, the perceived impact on innovation and research was discussed, focusing on the perceived impact within the field of antioxidants. The interview deliberated on the position of EFSA, as well as perceived advantages and disadvantages of the NHCR, again focussing on the field of antioxidants. If there were problems according to the interviewee which were due to this regulation, solutions were asked. Finally, the used standards for scientific substantiation were addressed.

All interviews, which were conducted in Dutch, lasted 30 to $60 \mathrm{~min}$ and audio recordings were used to transcribe the interviews. All participants were requested to correct transcriptions.

${ }^{3}$ Due to dynamics of the interviews, three questions were added throughout the interviews and the order of questions was changed. 


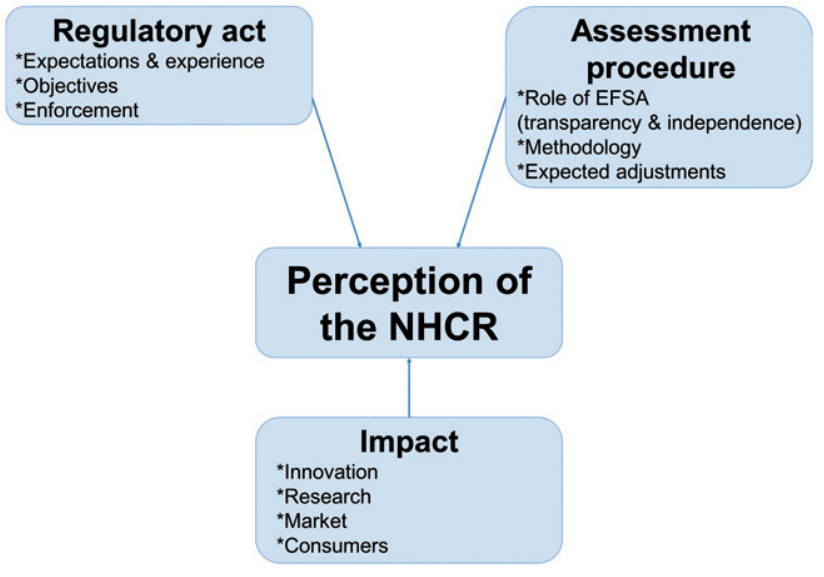

Figure 1. Web of themes.

\section{Data analysis}

The transcriptions were analyzed through a systematic approach of directed content analysis to identify key concepts, using the existing theoretical framework (section "Theoretical framework') (Hsieh \& Shannon, 2005). After reviewing the theoretical framework as well as the aim and research questions of the study, transcriptions were read intensively and repeatedly. Since the aim of this study was to identify all relevant issues with the NHCR raised by interviewees, all presented arguments and issues were highlighted. Secondly, the highlighted passages were coded with pre-determined codes, based on the theoretical framework. Thirdly, new codes were given to passages without a predetermined code. Based on these identified concepts and their relationships, the theoretical framework was adjusted. Finally, by comparing the initial theoretical framework to the rebuilt framework and by addressing similarities and differences in theoretical concepts, the final framework was build (depicted in Figure 1). All transcriptions were analyzed through this systematic approach by two members of the research team to reduce the possibility of the informed bias raised by the use of a directed approach (Hsieh \& Shannon, 2005). Furthermore, all quotes used in the paper were anonymized by avoiding the use of any names, brand names and industry names.

\section{Results and discussion}

Figure 1 depicts the identified themes influencing a stakeholder's perception of the NHCR. The interviews not only confirmed the themes described in the theoretical framework, but they also identified various additional concepts within these themes as shown in Figure 1. Therefore, the themes comprise the following: (i) the regulatory act itself; (ii) the assessment procedure; and (iii) the impact of the NHCR. These themes are discussed below.

\section{Regulatory act}

\section{Expectations and experience}

Experiences of various interviewees did not live up to their expectations, leading to disappointment on different aspects of the NHCR, viz. the assessment procedure, the time needed for implementation and the current effectiveness. Various industrials expected, based on publications and presentations previous to the enactment of the NHCR, the possibility to use graded evidence for substantiation with probable, possible and convincing evidence for a claimed effect. This is however not allowed under the NHCR, only generally accepted or newly developed scientific evidence establishing a cause and effect relationship is considered to be sufficient to substantiate a claim (Gilsenan, 2011). The submitted substantiation was varying strongly: some dossiers were not based on scientific evidence where others built on high quality human intervention studies, which exemplifies the different expectations of applicants (European Commission, 2013).

A nutritional scientist mentions debatable claims are still on the market: "You can still claim almost everything you wanted to claim earlier, if you use one of the nutrients on the positive list". The consumer representatives also consider the NHCR to be barely effective: although some non-substantiated claims are gone, many possibilities to use claims still exist and consumers can still be misled.

As literature on expectations of performance and consumer satisfaction explains, these disconfirmed expectations (here: positive expectations followed by negative experiences) are shown to result in psychological discomfort and a negative hedonic state (Anderson, 1973; Festinger, 1962; Greenwald \& Ronis, 1978; Webb \& Worchel, 1993).

\section{Objectives}

The objectives of the NHCR are prioritized differently by the interviewees: although all stakeholder groups feel that harmonization of national regulatory provisions is an objective of the NCHR, industrials and regulatory experts specifically point out the prevention of medical claims, whereas regulatory experts and nutritional scientists focus also on scientific substantiation of claims. The aim of protecting consumers from being misled is recognized by industrials, nutritional scientists and consumer representatives. These discrepancies between stakeholders in prioritization of objectives could be counteracted by providing more clarity on the factual objectives of the regulatory act.

Although many stakeholders feel the NHCR effectively protects consumers from being misled, a consumer representative believes that the NHCR does not live up to its objective: "Consumers are still misled. Antioxidants are a good theme in that case, it is quite clear you cannot claim anything on that. The idea of extra antioxidants in nutrition is actually fully undermined, so you cannot claim anything on it, and still you can easily find these claims'. In contrast, other interviewees (mainly industrials) feel the objective of consumer protection is overreached by enactment of the NHCR. Accomplishment of other objectives is also questioned by interviewees, as nutritional scientists question the stimulation of innovation and competitiveness: "You see companies are investing less in nutrition and health'. To meet the various objectives, the need for more transparency and enforcement is emphasized by many interviewees.

\section{Enforcement}

During the interviews, various issues arise concerning the enforcement of the NHCR. Considerable uncertainty exists on enforcement strategies, priorities and capabilities within the Netherlands as well as in other Member States. Various interviewees consider the establishment of a level playing field in the market of functional foods to depend on comparable enforcement throughout the EU, but the development of such comparable enforcement is questioned. The uncertainties surrounding the use of claims is exemplified by various stakeholders by the case of antioxidants, where mentioning the content of antioxidants is by some considered to be an implicit health claim, but can also be seen as a nutrition claim.

Increasing compliance by traditional enforcement of laws, with punishment as important component, as suggested by various interviewees, is confirmed in literature (Malloy, 2003). However, 
traditional enforcement poses several limitations: monitoring the industry highly increases costs and practical difficulties arise in identifying less visible violations (Malloy, 2003). Various stakeholders indicate to perceive that detecting violations of the NHCR is not considered to be a priority for the Netherlands Food and Consumer Product Safety Authority (NVWA). Therefore, due to the apparent lack of traditional enforcement methods, traditional enforcement alone does not seem to be the most suitable way to enforce this act, although punishment of offences could help to set an example and increase compliance to the NHCR.

The development of the self-regulating list by Dutch industrials, in consultation with the Ministry of Health, Welfare and Sports as well as the NVWA, is suggested by several stakeholders to be a good way to cope with the limited enforcement capacity, although various interviewees expect self-regulation not to be sufficient to properly enforce the NHCR (Keuringsraad, 2014; NVWA, 2014). Self-regulation is described in literature as a voluntary enforcement mechanism, and this voluntary aspect could decrease the credibility of the regulation (Haufler, 2001). Due to weak standards, a lack of transparency and ineffective enforcement with mild, non-public punishments, self-regulation is described to fail often, and is therefore considered to serve the industry rather than the public interest (Gunningham \& Rees, 1997). Contrary, when used in a form suitable to the regulation, self-regulation is shown to be effective. Setting rules and standards in cooperation with industries and with involvement of the government could lead to an effective form of selfregulation, with more flexibility and lower costs of enforcement (Gunningham \& Rees, 1997). Therefore, the use of self-regulation as a tool in enforcing the NHCR is suggested to be helpful.

\section{Assessment procedure}

Several industrials disagree with the current assessment procedure, but do not blame EFSA for the role they were given under the NHCR. Various nutritional scientists agree: "Considering the vagueness of the texts and what is written in the law, EFSA did everything very well'. Most interviewees consider EFSA as an important organization in implementing the NHCR, and regulatory experts feel EFSA is also the most appropriate organization to advise the EC independently and adequately. The quality of work of EFSA is questioned by some stakeholders, due to the high workload.

\section{Transparency and independence}

Transparency and independence are important aspects influencing a stakeholder's view on EFSA. Especially transparency of the assessment procedure was addressed by stakeholders during the interviews. Several supplement industrials question the transparency of EFSA, its procedures and its members, and some industrials feel the issued opinions are based on unclear criteria. A supplement industrial believes claims based on textbook knowledge versus claims based on new evidence are judged differently: "We know a lot about the mechanism of action of vitamins and minerals because deficiencies will cause disease. But with testing other substances, all patient studies are excluded'. In contrast, a food industrial recognizes EFSA as transparent and objective. Also a consumer representative feels that members of EFSA work independently to build good dossiers, and uniformity and transparency of opinions as well as handling of the dossiers are increased. Since transparency is shown to influence the credibility of assessments as here the procedure of reviewing scientific substantiation of a health claim, increased transparency of documents as scientific opinions will increase trust and legitimacy of EFSA and the following risk-management decisions of the EC (Klintman \& Kronsell, 2010; Kobusch, 2010; Schreider et al.,
2010). It will also decrease uncertainty and will improve the required decision-making time and public confidence in the processes (Frewer \& Salter, 2002; Moors, 2012). EFSA and the EC attempted to improve transparency by developing guidance documents and by publishing various documents as agendas, minutes and opinions of the scientific committee and all panels (Ernst \& Young, 2012; European Parliament and the Council, 2002; Finardi et al., 2012; Kobusch, 2010; Silano \& Silano, 2008). Increasing transparency even more could disrupt the stability and credibility of EFSA: publishing minority opinions and expert disagreements could alarm the public or could serve as ammunition for objectors (Finardi et al., 2012; Levidow \& Carr, 2007).

Although a regulatory expert feels the members of panels of EFSA will always be criticized on their independence, since experience in the field of nutrition research or food industry is necessary to evaluate health claims, during the interviews little was commented on the independence of EFSA. The efforts to improve independence of both EFSA and its members, by describing the independent position of board members and scientists involved in EFSA, therefore seem to pay off (Finardi et al., 2012; Klintman \& Kronsell, 2010).

\section{Methodology}

Some supplement industrials consider the used assessment criteria to be problematic: "Due to this regulation you, as an entrepreneur, are not allowed to use traditional knowledge to put information on your package'. The nutritional scientists agree that the substantiation criteria are hard to live up to, especially for the industry. However, a regulatory expert feels that EFSA's assessment procedure raised the standards for research: "EFSA is actually a huge peer review process. (...) EFSA or the regulation instigated the evaluation of a lot of these criteria and made them more explicit'".

The different interviewees do not agree on the effect of antioxidants, but believe antioxidants should not be characterized by antioxidant status of products or plasma. As emphasized by a regulatory expert: "Most biomarkers in the field of antioxidants are not valid. Therefore you should not use them, because if EFSA sees these invalid biomarkers being used in a study, it will be rejected'. This exemplifies the need to discuss used methodologies in nutrition research, as brought up by various stakeholders in the interviews. The high standards used by EFSA in evaluating scientific substantiation of health claims and the explicit need for human data are complimented by most interviewees, although some supplement industrials feel that the standards are too strict and too rigorous. Requiring the substantiation of health effects in an already healthy population is considered to reflect a pharmacological approach, which is also seen by a nutritional scientist and various food industrials. As explained by a nutritional scientist: "With respect to antioxidants, we should be striving for good tests which are indicative for health. At the same time it should be made clear that a good outcome does not imply five more healthy years'. Another nutritional scientist feels that the current approach highly differs from the set-up of dietary recommendations, where not only scientific evidence but also eminence (the expert opinion) is considered.

The focus of the current assessment procedure on clinical biomarkers in human intervention studies is considered to reflect this pharmacological approach. The possibility to claim that an antioxidant can protect against oxidative stress, as currently allowed for copper, was therefore not expected by an industrial stakeholder: "Not permitting the use of oxidative stress as a health outcome would not have surprised me, although I myself would not consider it to be a final effect'. This approach, with focussing on one or few outcome measures, is in literature 
suggested to be more suitable for drug testing than for nutrition research, where pleiotropic effects elicited by food should be researched (Bast et al., 2013; Blumberg et al., 2010; Heaney, 2008; Van Ommen \& Stierum, 2002; Weseler \& Bast, 2012). Several industrials and nutritional scientists feel new research methodologies therefore should be developed to test the effect of nutrition on health, which should be based on a revised definition of health. The official WHO definition originates from 1948: "Health is a state of complete physical, mental and social wellbeing and not merely the absence of disease or infirmity'. (WHO, 2006). Today, health is more about the ability to adapt to specific circumstances and therefore needs a more individual approach (Editorial, 2009; Huber et al., 2011; Kussmann et al., 2006; van Ommen et al., 2009; Van Ommen \& Stierum, 2002). With a more accurate definition of health, proper research methodologies can be developed to measure the effect of nutrition on maintaining health (Elliott et al., 2007).

Different methods are proposed in literature to ensure such a personal approach, as using nutrigenomics and phenotyping individuals (Astley \& Elliott, 2007). However, the methodology considered most suitable by various interviewees to test nutritional effects on health is the challenge test: an experimental setup where the system of a subject is put under pressure with a challenge, and the ability to resist or to recover from the impact is the marker for health. Examples of such challenge tests are the oral glucose tolerance test (OGTT), the oral lipid tolerance test (OLTT) and the postprandial challenge test (PCT) (Pellis et al., 2012; WHO, 1999). The influence of a food product or functional ingredient on this disturbance can be studied in this way (Pellis et al., 2012; van Ommen et al., 2009; Weseler \& Bast, 2012). These tests are considered to show the short-term effect of nutrition on health more accurately. Therefore, various interviewees expect these tests to be helpful in the future substantiation of health claims.

\section{Suggested adjustments}

Various possible adjustments to the assessment procedure are suggested by several stakeholders, mainly referring to the issue of botanical claims of which scientific substantiation is not reviewed yet. Amongst these botanical claims several antioxidant claims are seen by a stakeholder. These dossiers will not be reviewed before the MS agree upon the required assessment procedure, on which the Commission published a discussion paper in 2012 (Mathioudakis, 2013). Many interviewees are disappointed that these claims are still on hold, and various solutions are offered. Mainly supplement industrials emphasize these claims should be assessed differently under the NHCR, in a procedure more suitable to review the effectiveness of botanicals and which would allow claims to be based on traditional use (alike medicine). This is also the point of view of five of $26 \mathrm{MS}$ in the discussion paper published by the Commission in 2012, which would lead to a different treatment of botanicals requiring new rules for the use of these products in foods (Mathioudakis, 2013). However, many other interviewees, as well as seven other MS described in the discussion paper, feel these claims should be assessed via the currently used procedure and no exception should be made for botanicals compared to other ingredients in foods (Mathioudakis, 2013). These interviewees feel treating botanicals differently would undermine the NHCR. The position of an interviewee and expectations on how this issue will be handled is shown to influence a stakeholder's view of the NHCR.

\section{Impact}

Most interviewees see less innovation is taking place, due to the high demands and costs required to substantiate a claim. As an industrial exemplifies with the case of antioxidants: "Innovation in and research on antioxidants is not a very interesting field at the moment. I believe it is faded glory, and consumers are fed up with it'. An industrial feels these requirements favor bigger companies while decreasing innovation possibilities for smalland medium-sized companies, and a nutritional scientist feels the NHCR hereby leads to an impoverishment of reviewing health effects of products, because when assessing a health claim only one ingredient within a full product is evaluated. Various interviewees see that firms start to work around the regulation. These firms are seen to look for loopholes in the regulation by repositioning their product, e.g. a medicinal product or create mismatch products (products either (i) not regularly connected to health bearing a health claim; or (ii) bearing an approved health claim on one nutrient, but emphasizing this effect on another ingredient without an authorized health claim). Other firms are perceived to adopt a defensive position by using different communication strategies than claims or focussing on different unique selling points of their product than health.

The number of approved claims is suggested to determine the competitive landscape: rejection of the majority of claims is expected to reduce developments in functional foods (Moors, 2012). With the majority of antioxidant claims being rejected, the perceived reduction in innovation can be explained easily. In order to stimulate innovation after this round of rejection, the focus should rather be on new possibilities to assess health claims more positively (Moors, 2012). Despite the apparent inhibition of innovation, a consumer representative favors the positive effect of the NHCR on reducing consumer misleading.

Regarding the impact of the NHCR on research, differing opinions are expressed by stakeholders: a consumer representative sees no effect of the NHCR, since research is focussed on dietary patterns and is not targeted at specific components, where other interviewees feel the impact is hardly measureable due to the variance across institutes. Most industrials see less research is taking place, since it is highly connected to innovation. Investments in research are considered to be risky because the probability to get a claim is low, as stated by an industrial: "When we started questioning the substantiation of antioxidant claims, we decided to lose all of them. They are now prohibited to be used in our company'. A regulatory expert emphasizes, however, that lower investments in research could also be due to the economic crisis. Other interviewees perceive the NHCR to stimulate research: new research concepts are developed and the established assessment criteria could serve as motive to perform higher quality research.

Several interviewees perceive the NHCR negatively affects the market. A nutritional scientist thinks that companies should stop complaining but develop a strategy together to deal with the required costs and time. Another suggested approach to counteract the negative effect of the NHCR on the market is to reduce the number of mismatch products on the market by providing clarity on the botanicals issue, enforcing the NHCR and introducing nutrient profiles. These nutrient profiles, nutritional requirements which must be met by foods bearing claims, are under development (EFSA, 2013). Still, a nutritional scientist believes the market of functional foods is past its prime and although the influence of the NHCR is considered not to be positive, less will be invested in this area.

Many supplement industrials feel the NHCR decreases possibilities to inform consumers about health effects, although in literature health claims are considered to be a tool to educate consumers about health and healthy products, and to stimulate healthy choices in the diet (Mitra et al., 1999; Roe et al., 1999; van Trijp \& Van der Lans, 2007; Williams, 2005). Literature however questions this educational effect, since consumers do not 
seem to believe statements made by industry (Menozzi et al., in press; Teisl \& Levy, 1997).

Several interviewees notice decreasing interest and trust of consumers in claims, which is confirmed in literature: less exposure decreases the acceptance and interest of consumers (Dean et al., 2012). Trust is suggested by a supplement industrial to be increased by informing consumers about the authorization system of claims and the scientific substantiation required, since consumers - unaware of the current situation - request an independent institution to assess and approve a claim (Gray, 2013). Although increased trust in health claims due to the NHCR is expected by various stakeholders, they still question to which extent the permitted claims are understood.

These conflicting ideas on the effect of the NHCR on innovation of functional food products and especially of food products containing antioxidants, as well as the perceived effects on research, the market and consumers, seem to highly influence a stakeholder's perception of the NHCR.

\section{Strengths and limitations}

The interviews, carried out in person by the first author, were conducted with seven industrials, two regulatory experts, three nutritional scientists and two consumer representatives. The industry group was large compared to the other stakeholder groups, but since this group was very diverse and consisted of both supplement industrials and food industrials, they are not overrepresented in this study. Although the number of interviewees was relatively small, in the end no new findings were extracted from the conducted interviews and therefore the point of saturation was reached. Since the amount of experts in the field of antioxidants dealing with the NHCR is very limited, selecting participants via purposive sampling and snowball sampling was considered appropriate as discussed in the section "Selection of participants".

Still, the focus on food products containing antioxidants of this study was not fully reflected in the results, since not all stakeholders focussed solely on food products containing antioxidants. This led to more general answers on the use of the NHCR in the field of functional foods, with the case of antioxidants more often used as an example. However, the participating stakeholders were all experts in the use of the NHCR in their organization and came into contact with products containing antioxidants directly and indirectly. Therefore, all interviews were used for data collection and analysis.

\section{Recommendations for improving the NHCR}

The grounds for disproving all virtual identified antioxidant claims are entailed in Figure 1: (i) the regulatory act itself, including (a) expectations and experience, (b) objectives and (c) enforcement; (ii) the assessment procedure, involving (a) transparency and independence, (b) methodology and (c) suggested adjustments; and (iii) the impact of the NHCR, including the impact on (a) innovation, (b) research, (c) the market and (d) consumers.

\section{Strengths of the NHCR}

Most interviewed stakeholders are seen to agree upon the need for the NHCR in protecting consumers from misleading and harmonizing regulations throughout Europe. Therefore, the requirement for scientific substantiation of commercial outings on antioxidant containing food products and other functional foods are welcomed. The strengths of the NHCR are considered to be addressing these needs, and similarly the possibility that consumers' trust in claims will be increased due to the NHCR is favorable in the eyes of different stakeholders. Another positive aspect mentioned by some interviewees is that over time the transparency of EFSA in the assessment procedure of proposed claims is highly increased.

\section{Concerns with the NHCR}

The main concerns addressed within the interviews involve the following concepts: (i) enforcement of the NHCR, (ii) methodology of scientific substantiation and (iii) perceived impact. Even though the NHCR entered into force in July 2007 and the list of approved claims was published in May 2012, substantial uncertainty seems to exist on the enforcement of the NHCR. Enforcement is considered to be important for the harmonization throughout Europe, and although no agreement is reached upon the preferred form of enforcement, its implementation is requested by several stakeholders.

The assessment procedure as executed by EFSA is highly debated by various interviewees. The dossiers firstly submitted are shown to be based on evidence highly varying in scientific quality, which exemplifies the differences in expectations of various applicants of the whole procedure. The ideas of stakeholders on methodology used in nutrition research not only differ from each other, but also these views seem to be deviating fundamentally from the use of nutrition research within the NHCR where apparently a more pharmacological approach is used in the assessment procedure. This reveals an underlying issue: how should the effects of nutrition on health be tested; and how should health be defined?

The effects of the NHCR on innovation, research, the market and consumers are experienced differently by various stakeholders. These mostly intuitive effects perceived by a stakeholder are shown to either negatively or positively affect the perception of the NHCR. However, currently no accurate facts about this impact are available.

\section{The case of antioxidants}

The identified issues are helpful in explaining the disproval of the large amount of proposed health claims on antioxidant containing products. Not only the expected quality of scientific substantiation appeared to differ highly from the required scientific substantiation, the methods to study antioxidants are also debated and the health effects of antioxidants might be more subtle than required under the current assessment procedure of health claims.

Antioxidants seem to be an interesting theme in the enforcement of the NHCR, since where content claims are mostly considered to be a nutrition claim, claiming antioxidants in a product can be seen as an implicit - and sometimes prohibited health claim. Also innovation and research on antioxidants, as well as on the market of antioxidant containing products and consumer perception thereof are suggested to be highly influenced by the entry into force of the NHCR, which could explain opinions of stakeholders on the NHCR (either positive or negative, depending on their view on the effects of antioxidants).

\section{Suggestions for improvement}

Next to explaining the disproval of most proposed health claims on antioxidants, the identified strengths and weaknesses give the opportunity to identify specific aspects to improve. Directly related to the regulatory act itself is the enforcement of the NHCR, on which clarification of actions of Member States could shed light. The issue of botanical claims should be resolved by the European Parliament and the Commission, to ensure fair competition on the market of functional foods and to enhance the effectiveness of the NHCR.

However, most improvements do not follow directly from problems with the NHCR itself, but from the public debate 
about the NHCR as well as from issues with procedures developed under the regulatory act. The perceived impact of the NHCR on innovation, research, the market and consumers is seen to highly influence a stakeholder's perception of the NHCR. Currently, this discussion seems to be extremely driven by instincts and intuition of experts in the field, without being based on facts. To ensure this debate reflects the actual situation, quantitative measurements of the impact of the NHCR are required. These effects could be studied by comparing resources allocated to both innovation and research in different institutes before the entry into force of the NHCR to the current situation, and numbers on the market of antioxidant containing food products and other functional foods can be compared with numbers of the period before the NHCR. Nevertheless, consumer effects are more difficult to measure quantitatively. The impact of the NHCR on consumers could be assessed by reviewing their attitude and willingness to pay towards functional foods carrying specific claims.

The main issue identified through these interviews with experts in the field of antioxidants is the assessment procedure, with pointing out methodological problems next to the distinct ideas in science about health effects of nutrition. Although antioxidants serve as a good model, these problems do not seem to arise solely in this field. To improve both dossiers building and the assessment procedure, new methodology on how to assess health effects elicited by antioxidants and other nutritional substances should be developed and implemented, following from scientific consensus reached on the definition of health.

\section{Conclusion}

The NHCR was created to regulate commercial outings of health benefits elicited by nutrition. This research was initiated after most proposed antioxidant claims were seen to fail the assessment procedure. To unravel the grounds for disproving the putative health claims, the perception of stakeholders of the NHCR was reviewed by conducting semi-structured in-depth interviews with 14 stakeholders. Most proposed antioxidant claims are seen to be refused based on the quality of scientific substantiation, not only due to the use of scientific methods on which no consensus has been reached, but also due to the differences in expectations of submitters versus requirements of the assessors. Although most stakeholders welcome the NHCR as means to fight consumer misleading and harmonize international regulations, a clear need for improvement in the application of the NHCR is shown. An independent assessment of the impact of the NHCR on innovation, research, the market of antioxidants and functional foods, and consumer acceptance of nutrition and health claims, next to more clarity on enforcement procedures within Member States would help to improve the perception of the NHCR amongst stakeholders. However, most importantly, the need to define health is once more emphasized due to its importance in the assessment procedure of health effects of antioxidants and other functional ingredients.

Although the current case study focuses on the perception of the NHCR related to food products and functional ingredients containing antioxidants in the Netherlands, it can easily be extrapolated to other fields of functional ingredients and to the situation in other Member States, since the regulation is not only affecting functional foods containing antioxidants or solely Dutch stakeholders but the whole European functional food market. With highly diverging perceptions of stakeholders, the current effectiveness of the NHCR can be questioned. The views of different stakeholders on enforcement, methodology and impact could help to focus the discussion on the NHCR in capturing health effects.

\section{Acknowledgements}

The authors thank all interviewees for their participation in the study. We thank Nathalie Baltus for assisting in the transcription of interviews and brainstorms about the analysis. Prof. Dr. Ellen Vos is gratefully acknowledged for fruitful discussions on the manuscript.

\section{Declaration of interest}

The authors declare no conflicts of interest.

\section{References}

Anderson RE. 1973. Consumer dissatisfaction: the effect of disconfirmed expectancy on perceived product performance. J Mark Res 10:38-44.

Astley SB, Elliott RM. 2007. The European Nutrigenomics Organisation: linking genomics, nutrition and health research. J Sci Food Agric 87: 1180-1184.

Bast A, Briggs WM, Calabrese EJ, Fenech MF, Hanekamp JC, Heaney R, Rijkers G, et al. 2013. Scientism, legalism and precaution-contending with regulating nutrition and health claims in Europe. EFFL 8:401-409.

Blumberg J, Heaney RP, Huncharek M, Scholl T, Stampfer M, Vieth R, Weaver CM, Zeisel SH. 2010. Evidence-based criteria in the nutritional context. Nutr Rev 68:478-484.

Bremmers H, van der Meulen B, Purnhagen K. 2013. Multi-stakeholder responses to the European Union health claims requirements. J Chain Network Sci 13:161-172.

de Boer A, Vos E, Bast A. 2014. Implementation of the nutrition and health claim regulation - the case of antioxidants. Regul Toxicol Pharmacol 68:475-487.

Dean M, Lampila P, Shepherd R, Arvola A, Saba A, Vassallo M, Claupein E, et al. 2012. Perceived relevance and foods with health-related claims. Food Qual Prefer 24:129-135.

DiCicco-Bloom B, Crabtree BF. 2006. The qualitative research interview. Med Educ 40:314-321.

Editorial. 2009. What is health? The ability to adapt. Lancet 373:781.

EFSA. 2012. "General function" health claims under Article 13. Available at: http://www.efsa.europa.eu/en/topics/topic/article13.htm. Accessed on 11 April 2014.

EFSA. 2013. EFSA: FAQ on nutrition and health claims. Available at: http://www.efsa.europa.eu/en/faqs/faqnutrition.htm?wtrl=01. Accessed on 11 April 2014.

EFSA. 2014a. About the NDA Panel and the Nutrition Unit. Available at: http://www.efsa.europa.eu/en/nda/aboutnda.htm. Accessed on 11 April 2014.

EFSA. 2014b. Claims on disease risk reduction and child development or health under Article 14. Available at: http://www.efsa.europa.eu/en/ topics/topic/article14.htm. Accessed on 11 April 2014.

EFSA. 2014c. "New function" health claims under Article 13.5. Available at: http://www.efsa.europa.eu/en/topics/topic/article13-5. htm. Accessed on 11 April 2014.

EFSA. 2014d. Nutrition and health claims. Available at: http://www.efsa. europa.eu/en/topics/topic/nutrition.htm. Accessed on 11 April 2014.

Elliott R, Pico C, Dommels Y, Wybranska I, Hesketh J, Keijer J. 2007. Nutrigenomic approaches for benefit-risk analysis of foods and food components: defining markers of health. Br J Nutr 98:1095-1100.

Ernst \& Young. 2012. External evaluation of EFSA - final report. Available at: http://www.efsa.europa.eu/en/keydocs/docs/efsafinal report.pdf. Accessed on 20 October 2014.

Europe Press Releases. 2006. Questions and answers on health and nutrition claims. Available at: http://europa.eu/rapid/press-release MEMO-06-200_en.htm?locale=en. Accessed on 04 April 2013.

European Commission. 2012. Commission Regulation (EU) No 432/2012 of 16 May 2012 establishing a list of permitted health claims made on foods, other than those referring to the reduction of disease risk and to children's development and health. OJ L 55:1-40.

European Commission. 2013. EU Register on nutrition and health claims. Available at: http://ec.europa.eu/nuhclaims/?event=search\&CFID $=$ 335086\&CFTOKEN $=$ bb484f431b227bd1-79366084-B936-26BA-A09 3EC372F6F1B31\&jsessionid $=9312 \mathrm{c} 835 \mathrm{f} 5666 \mathrm{f} 4342 \mathrm{c} 4403366511152 \mathrm{f}$ 434TR. Accessed on 11 April 2014.

European Parliament and the Council. 2002. Regulation (EC) No 178/ 2002 of the European Parliament and of the Council of 28 January 2002 laying down the general principles and requirements of food law, establishing the European Food Safety Authority and laying down procedures in matters of food safety. OJ L 31:1-24. 
European Parliament and the Council. 2006. Regulation (EC) No 1924/ 2006 of the European Parliament and of the council of 20 December 2006 on nutrition and health claims made on foods. OJ L 404:9-25.

Festinger L. 1962. A theory of cognitive dissonance. Stanford: Stanford University Press.

Finardi C, Pellegrini G, Rowe G. 2012. Food safety issues: from enlightened elitism towards deliberative democracy? An overview of EFSA's “Public Consultation"' instrument. Food Policy 37:427-438.

Freeman RE. 1984. Strategic management: a stakeholder approach. Boston: Pitman.

Frewer L, Salter B. 2002. Public attitudes, scientific advice and the politics of regulatory policy: the case of BSE. Sci Public Policy 29: 137-145.

Gilsenan M. 2011. Nutrition \& health claims in the European Union: a regulatory overview. Trends Food Sci Technol 22:536-542.

Gray N. 2013. Most consumers don't know what EFSA is, experts find. Available at: http://www.nutraingredients.com/Consumer-Trends/ Most-consumers-don-t-know-what-EFSA-is-experts-find. Accessed on 11 April 2014.

Greenwald AG, Ronis DL. 1978. Twenty years of cognitive dissonance: case study of the evolution of a theory. Psychol Rev 85:53-57.

Gunningham N, Rees J. 1997. Industry self-regulation: an institutional perspective. Law Policy 19:363-414.

Haufler V. 2001. A public role for the private sector: Industry selfregulation in a global economy. Washington, DC: Carnegie Endowment.

Heaney RP. 2008. Nutrients, endpoints, and the problem of proof. J Nutr 138:1591-1595.

Hoad D. 2011. Scientific Method and the Regulation of Health and Nutritional Claims by the European Food Safety Authority. Bull Sci Technol Soc 31:123-133.

Hsieh H-F, Shannon SE. 2005. Three approaches to qualitative content analysis. Qual Health Res 15:1277-1288.

Huber M, Knottnerus JA, Green L, Horst HVD, Jadad AR, Kromhout D, Leonard B, et al. 2011. How should we define health? Br Med J 343: d4163.

Jensen KK, Sandøe P. 2002. Food safety and ethics: the interplay between science and values. J Agric Environ Ethics 15:245-253.

Keuringsraad. 2014. Database claimsverordening. Available at: http:// keuringsraad.nl/Database-claimsverordening-en-indicatieve-lijst.

Accessed on 29 April 2014.

Klintman M, Kronsell A. 2010. Challenges to legitimacy in food safety governance? The case of the European Food Safety Authority (EFSA). Eur Integr 32:309-327.

Kobusch A. 2010. Linking the levels: independence and influence in the European two-tiered network of food safety agencies. Third Biennial Conference "Regulation in the Age of Crises" of the ECPR Standing Group on Regulatory Governance, Dublin. Available at: http://regulation.upf.edu/dublin-10-papers/3D2.pdf. Accessed on 17 November 2014.

Kussmann M, Raymond F, Affolter M. 2006. OMICS-driven biomarker discovery in nutrition and health. J Biotechnol 124:758-787.

Levidow L, Carr S. 2007. Europeanising advisory expertise: the role of 'independent, objective and transparent' scientific advice in agribiotech regulation. Environ Plann C Gov Policy 26:880-895.

Lucas SR. 2014. Beyond the existence proof: ontological conditions, epistemological implications, and in-depth interview research. Qual Quantity 48:387-408.

Malloy TF. 2003. Regulation, compliance and the firm. Temple Law Rev $76: 451-532$

Mansfield E. 1991. Academic research and industrial innovation. Res Policy 20:1-12.

Mason M. 2010. Sample size and saturation in $\mathrm{PhD}$ Studies using qualitative interviews. Forum Qual Soc Res 11: Art 8.

Mathioudakis B. 2013. Presentation International Conference. Botanicals in food supplements, Rome. Available at: http://www.salute.gov.it/ imgs/C_17_EventiStampa_163_intervisteRelatori_itemInterviste_8_ fileAllegatoIntervista.pdf. Accessed on 20 October 2014.

Menozzi D, Halawany-Darson R, Mora C, Giraud G. In press. Motives towards traceable food choice: a comparison between French and Italian consumers. Food Control 49:40-48.

Mitra A, Hastak M, Ford GT, Ringold DJ. 1999. Can the educationally disadvantaged interpret the FDA-mandated nutrition facts panel in the presence of an implied health claim? J Public Policy Mark 18:106-117.
Moors EH. 2012. Functional foods: regulation and innovations in the EU. Innovation 25:424-440.

NDA Panel EFSA. 2009. Scientific opinion on water-soluble tomato concentrate (WSTC I and II) and platelet aggregation Scientific substantiation of a health claim related to water-soluble tomato concentrate (WSTC I and II) and platelet aggregation pursuant to Article 13(5) of Regulation (EC) No 1924/2006. EFSA J 1101:1-15.

NDA Panel EFSA. 2010. Scientific opinion on the modification of the authorisation of a health claim related to water-soluble tomato concentrate and helps to maintain a healthy blood flow and benefits circulation pursuant to Article 13(5) of Regulation (EC) No 1924/2006 following a request in accordance with Article 19 of the Regulation (EC) No 1924/2006. EFSA J 8:1689.

NDA Panel EFSA. 2012. Scientific opinion on the substantiation of a health claim related to cocoa flavanols and maintenance of normal endothelium-dependent vasodilation pursuant to Article 13(5) of Regulation (EC) No 1924/2006. EFSA J 10:2809.

Nelson R. 1993. National innovation systems: a comparative analysis. Oxford, New York, Toronto: Oxford University Press.

NVWA. 2014. Claims levensmiddelen - Preventief toetsen gezondheidsclaims bij Keuringsraad. Available at: http://www.vwa.nl/onderwerpen/regels-voor-ondernemers-eten-en-drinken/dossier/claims-levens middelen/gezondheidsclaims-correct-gebruik/preventief-toetsengezondheidsclaims-bij-keuringsraad. Accessed on 29 April 2014.

Oliver RL. 1980. A cognitive model of the antecedents and consequences of satisfaction decisions. J Mark Res 17:460-469.

Pellis L, van Erk MJ, van Ommen B, Bakker GC, Hendriks HF, Cnubben NH, Kleemann R, et al. 2012. Plasma metabolomics and proteomics profiling after a postprandial challenge reveal subtle diet effects on human metabolic status. Metabolomics 8:347-359.

Ritchie J, Lewis J. 2003. Qualitative research practice: a guide for social science students and researchers. London: Sage.

Roe B, Levy AS, Derby BM. 1999. The impact of health claims on consumer search and product evaluation outcomes: results from FDA experimental data. J Public Policy Mark 18:89-105.

Schreider J, Barrow C, Birchfield N, Dearfield K, Devlin D, Henry S, Kramer M, et al. 2010. Enhancing the credibility of decisions based on scientific conclusions: transparency is imperative. Toxicol Sci 116: $5-7$.

Silano M, Silano V. 2008. The fifth anniversary of the European Food Safety Authority (EFSA): mission, organization, functioning and main results. Fitoterapia 79:149-160.

Tansey O. 2007. Process tracing and elite interviewing: a case for nonprobability sampling. PS 40:765-772.

Teisl MF, Levy AS. 1997. Does nutrition labeling lead to healthier eating? J Food Distrib Res 28:18-27.

van Ommen B, Keijer J, Heil SG, Kaput J. 2009. Challenging homeostasis to define biomarkers for nutrition related health. Mol Nutr Food Res 53:795-804.

Van Ommen B, Stierum R. 2002. Nutrigenomics: exploiting systems biology in the nutrition and health arena. Curr Opin Biotechnol 13: 517-521.

van Trijp H, Van der Lans IA. 2007. Consumer perceptions of nutrition and health claims. Appetite 48:305-324.

Verhagen H, Vos E, Francl S, Heinonen M, van Loveren H. 2010. Status of nutrition and health claims in Europe. Arch Biochem Biophys 501: $6-15$.

Webb WM, Worchel S. 1993. Prior experience and expectation in the context of crowding. J Pers Soc Psychol 65:512-521.

Weseler AR, Bast A. 2012. Pleiotropic-acting nutrients require integrative investigational approaches: the example of flavonoids. J Agric Food Chem 60:8941-8946.

WHO. 1999. Part 1: diagnosis and classificaion of diabetes mellitus. Available at: http://whqlibdoc.who.int/hq/1999/who_ncd_ncs_99.2. pdf. Accessed on 17 November 2014.

WHO. 2006. Constitution of the World Health Organization. Available at: www.who.int/governance/eb/who_constitution_en.pdf. Accessed on 11 April 2014.

Williams P. 2005. Consumer understanding and use of health claims for foods. Nutr Rev 63:256-264.

Woodruff RB, Cadotte ER, Jenkins RL. 1983. Modeling consumer satisfaction processes using experience-based norms. J Mark Res 20 296-304. 